\title{
Targeted Sequencing of Circulating Cell Free DNA Can Be Used to Monitor Therapeutic Efficacy of Tyrosine Kinase Inhibitors in Non-small Cell Lung Cancer Patients
}

\author{
CHIUAN-CHIAN CHIOU ${ }^{1,2,3 \#}$, CHIH-LIANG WANG ${ }^{3,4 \#}$, JI-DUNG LUO ${ }^{5}$, \\ CHIEN-YING LIU ${ }^{3,4}$, HOW-WEN KO ${ }^{3}$ and CHENG-TA YANG ${ }^{3,6}$ \\ ${ }^{1}$ Department of Medical Biotechnology and Laboratory Science, \\ College of Medicine, Chang Gung University, Taoyuan, Taiwan, R.O.C.; \\ ${ }^{2}$ Graduate Institute of Biomedical Sciences, College of Medicine, Chang Gung University, Taoyuan, Taiwan, R.O.C.; \\ ${ }^{3}$ Department of Thoracic Medicine, Linkou Chang Gung Memorial Hospital, Taoyuan, Taiwan, R.O.C.; \\ ${ }^{4}$ Department of Medicine, College of Medicine, Chang Gung University, Taoyuan, Taiwan, R.O.C.; \\ ${ }^{5}$ Bioinformatics Resource Center, The Rockefeller University, New York, NY, U.S.A.; \\ ${ }^{6}$ Department of Respiratory Therapy, College of Medicine, Chang Gung University, Taoyuan, Taiwan, R.O.C.
}

\begin{abstract}
Background/Aim: Circulating tumor DNA (ctDNA) bears specific mutations derived from tumor cells. The amount of mutant ctDNA may reflect tumor burden. In this study, we detected epidermal growth factor receptor (EGFR) mutations in ctDNA as a monitoring marker for the response of non-small cell lung cancer (NSCLC) patients to tyrosine kinase inhibitors (TKIs). Patients and Methods: Serial plasma samples from eight NSCLC patients during TKI treatment were collected. Libraries with barcoded adapters were constructed from ctDNA of these plasma samples using a PCR-based targeted DNA panel. The libraries were then sequenced for measuring EGFR mutations. In addition, carcinoembryonic antigen (CEA) was also measured in these patients. Results: In six patients who suffered disease progression (PD), five had elevated EGFR mutation reads before $P D$. In the two patients who did not develop $P D$, EGFR mutations remained undetectable in their plasma. The CEA levels were higher than the cutoff value in most samples and had a poor correlation with disease status. Conclusion: The mutation count of tumor-specific mutations can be a monitoring marker of TKI treatment in NSCLC patients.
\end{abstract}

This article is freely accessible online.

\#These Authors contributed equally to this study.

Correspondence to: Dr. Cheng-Ta Yang, Department of Thoracic Medicine, Linkou Chang Gung Memorial Hospital, Taoyuan 333, Taiwan, R.O.C. Tel: +886 33281200\#3601, e-mail: yang1946@ cgmh.org.tw

Key Words: Circulating tumor DNA, EGFR mutation, monitoring markers, non-small cell lung cancer.
Non-small cell lung cancer (NSCLC) is the most common histological subtype of lung cancer in developed countries. Latestage NSCLC has a high mortality rate and is a leading cause of death worldwide (1). Because some NSCLCs, in particular adenocarcinoma, bear mutations in the tyrosine kinase domain of epidermal growth factor receptor $(E G F R)$, tyrosine kinase inhibitors (TKIs) targeting mutant EGFR can effectively inhibit tumor growth and have been used to treat advanced NSCLC (24). Although EGFR-targeted therapy is effective, eventually tumors develop resistance to TKIs a few months to years after treatment because the tumor obtains a secondary mutation such as T790M or c-MET amplification (5-7). Therefore, these patients need frequent follow-up checks during treatment.

Traditionally, the follow-up checks during TKI treatment usually include imaging technologies, including computed tomography scan, X-ray imaging, and ultrasound scan. The imaging technologies detect alterations in tumor size and are usually restricted in the chest. Therefore, these technologies have limited sensitivity in detecting early progression and may miss metastatic tumors in distal parts of the body. Measurement of serum carcinoembryonic antigen (CEA) levels can be used to assess the treatment $(8,9)$. However, the CEA test has low sensitivity and specificity for lung cancer prognosis. Thus, the development of new markers is in demand.

Circulating tumor DNA (ctDNA) is released from dead cells, either by apoptosis or necrosis (10). Turnover of cancer tissues also releases ctDNA into the blood stream. Cancerderived ctDNA can thus be detected in peripheral blood (11). This ctDNA bears characteristics of the cancer cells, such as gene mutations $(9,12,13)$, hypermethylation (14), and structural variations (15-17). These characteristics make cancer diagnosis possible using ctDNA in the peripheral 
blood. In addition, because obtaining peripheral blood is relatively noninvasive and can be performed repeatedly, ctDNA in the blood is a promising source of markers for monitoring purposes. Currently, ctDNA has been shown to be useful in diagnosing cancer, guiding therapy, monitoring cancer relapse or progression, and predicting treatment outcome in many cancer types (18-20).

The detection of cancer-specific ctDNA in the blood is a challenge due to its low abundance in the background of wild type DNA. Detecting this type of DNA needs a method that is very sensitive and specific. Methods that have been reported to detect cancer-specific mutations in blood samples include the amplification refractory mutation system (21, 22), clamping PCR (23-25), droplet digital PCR (26-28), and next-generation sequencing (NGS) (29-31).

NGS is a powerful method for detecting cancer-related mutations. In the variety of NGS applications, targeted gene sequencing is easier to perform in clinical laboratories (32, 33). Multiple cancer-related genes from a selected panel can be sequenced in one assay. In addition, the PCR-based targeted sequencing panel only amplifies a limited number of exons, thus it can provide low-frequency mutation detection due to deep sequencing NGS has been used for the prediction or follow-up of cancer treatments. For example, it has been used for measuring ALK rearrangements for predicting the sensitivity of lung cancer to ALK tyrosine kinase inhibitors $(34,35)$, for monitoring different gene mutations in various tumor types during targeted therapies (36), and for detecting driver and resistance mutations in advanced NSCLC (12).

However, NGS has disadvantages including its high error rate (37), which limits its sensitivity for detecting mutant alleles in the background of wild type DNA. In practice, the mutant DNA must have an at least $2.5 \%$ allele frequency in order to be detected. Recently, molecular barcodes or SafeSeqS were introduced to eliminate PCR errors and thus have improved the sensitivity of mutant detection in the wild-type background (38).

In the current study, we hypothesized that an alteration in mutant counts in ctDNA reflects a change in tumor burden. We thus used NGS to detect cancer-related mutations in ctDNA to monitor disease progression during TKI treatment in NSCLC patients. In addition, we compared NGS results with CEA levels and imaging results.

\section{Patients and Methods}

Patients and IRB. Eleven patients with TNM stage IV adenocarcinoma were enrolled in this study. All of these patients carried at least an aEGFR mutation, which was verified by the Pathology Department of Chang Gung Memorial Hospital with the therascreen EGFR PCR Kit (Qiagen, Valencia, CA, USA). Written informed consent was obtained from all patients before sample collection. The study was approved by the Institutional Review Board, Chang Gung Memorial Hospital (with approval numbers
103-6944B and 103-1123B). All patients were treated with TKIs. Among these patients, three provided blood samples once before treatment, and eight provided serial blood samples for at least 6 months during follow-up. Serial blood samples were collected just before receiving EGFR TKI treatment, at 1, 3 and 5 weeks after taking the EGFR TKI treatment, and then every 3 months until disease progression or the end of this study. Blood samples were collected into EDTA tubes and centrifuged for $20 \mathrm{~min}$ at 2,000 $\times \mathrm{g}$ to separate plasma from blood cells. Plasma was stored at $-80^{\circ} \mathrm{C}$ until further analysis. Blood CEA levels were measured by immunoassay on an ADVIA Centaur XP (Siemens Diagnostics, Tarrytown, NY, USA). Chest CT was performed regularly every three months to evaluate the response to the EGFR TKI therapy and the disease status. RECIST criteria version 1.1 were used to determine the best response to the EGFR TKI treatment (39).

Purification and quantification of DNA. Circulating cell-free DNA was purified from $0.5-1 \mathrm{ml}$ of plasma with a QIAsymphony DSP circulating DNA Kit or QIAamp Circulating Nucleic Acid Kit (Qiagen) and eluted in $50 \mu \mathrm{l}$ Tris buffer, according to the manufacturer's instructions. The DNA concentration was estimated by using an Agilent Bioanalyzer (Agilent Technologies, Palo Alto, CA, USA) or quantitative PCR using the actin gene as an indicator.

Library construction and sequencing. A QIAseq Targeted DNA Custom Panel (CDHS-13297Z-33, Qiagen) was used to amplify targeted genes and construct a library. Briefly, each ctDNA aliquot was added to the reaction for fragmentation, end repair, and A-addition. Then, the barcoded adapters and DNA ligase were added to the mixture for the construction of a target library, which attached a barcode at the 5' end of each DNA strand. The library was purified by QIAseq beads to remove free adapters. The purified library was then enriched by eight PCR cycles using adapter primers and a pool of gene-specific primers. Next, the enriched library was subjected to 26 PCR cycles using universal primers, which added complete Illumina adapters for sequencing. The PCR products were purified and then sequenced on an Illumina MiSeq sequencer (Illumina, CA, USA), according to the manufacturer's instructions. Sequence data were analyzed with smCounter (40), which is an open source, barcodeaware variant caller based on the Bayesian model, and CLC genomics workbench (Qiagen). Original reads in the FASTQ file were processed in the order of adapter trimming, read aligning, barcode clustering, and primer region trimming. First, the adapter and barcode region were trimmed off. Then, the trimmed reads were aligned to the reference sequences, which created an alignment file. PCR errors were estimated by a clustering algorithm, which identified barcodes and combined them if one barcode had significantly more supporting reads than others. Then, the smCounter processed the individual target loci.

\section{Results}

Detecting EGFR mutations before TKI treatment. A total of 61 blood samples from 11 patients were subjected to targeted sequencing. Among them, 8 patients provided serial samples during the period of TKI treatment for at least 17 months or until PD, and the other 3 patients only provided blood samples once. Hence, the follow-up analysis was based on the serial samples from the 8 patients. The patient information is listed in Table I. The plasma samples were subjected to DNA extraction and NGS analysis for TKI- 


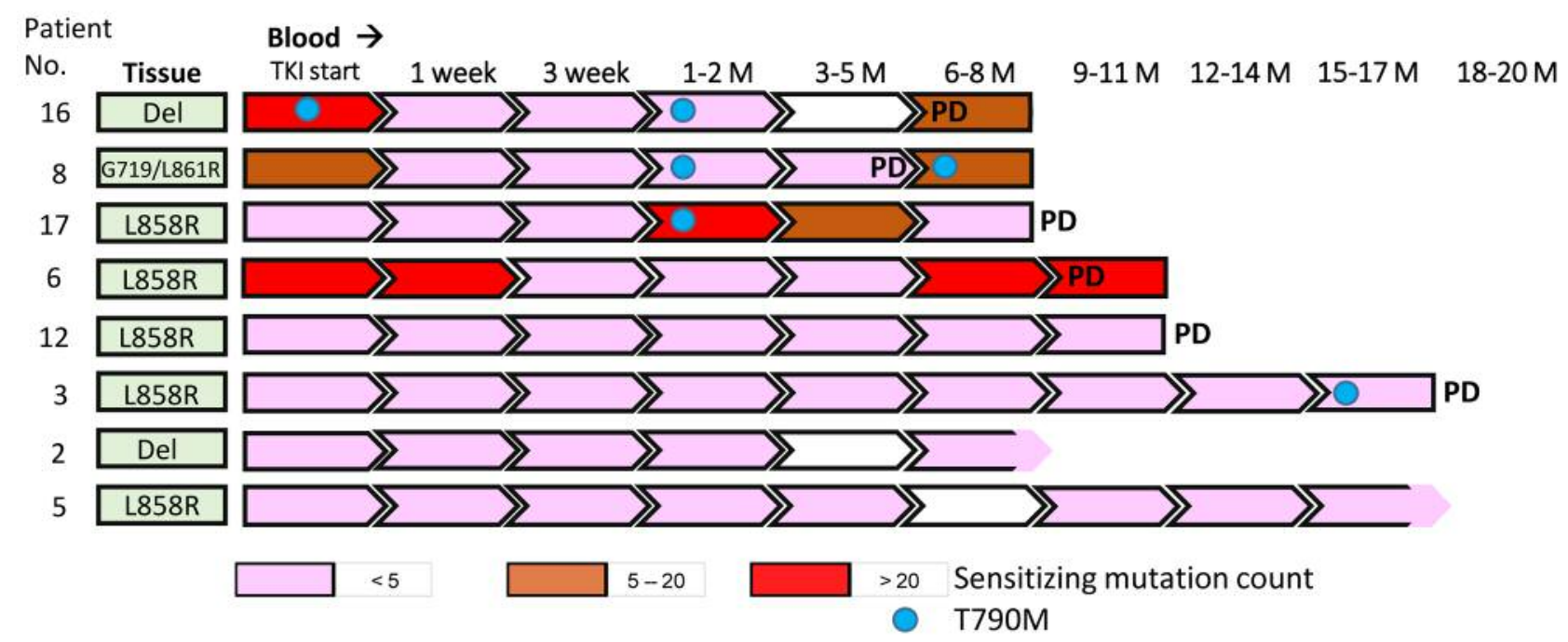

Figure 1. Detection of EGFR mutations during TKI treatment. All the patients had a TKI sensitizing mutation in the EGFR gene (the green roll). After initiating TKI treatment, blood samples were collected at the indicated times, and EGFR mutations in the plasma RNAs were measured by targeted sequencing. The matched mutations in both the blood and tissue samples were used as monitoring markers. Each box represents the mutation count at each sampling time. The closed boxes on the rightmost positions of the rolls represent progressive disease (PD). The open boxes on the rightmost positions of the rolls represent no disease progression at the end of the sampling.

Table I. Patient characteristics.

\begin{tabular}{|c|c|c|c|c|c|c|}
\hline \multirow[t]{2}{*}{ No. } & \multirow[t]{2}{*}{ Gender } & \multirow[t]{2}{*}{ Age } & \multirow[t]{2}{*}{ TKI } & \multicolumn{2}{|c|}{ EGFR mutation } & \multirow[t]{2}{*}{ Serially sampling } \\
\hline & & & & Tissue & Blood $^{\mathrm{a}}$ & \\
\hline 16 & M & 37 & Afatinib & Exon 19 del & Exon 19 del & Yes \\
\hline 8 & $\mathrm{~F}$ & 54 & Afatinib & G719A+L861R & $\mathrm{G} 719 \mathrm{~A}+\mathrm{L} 861 \mathrm{R}$ & Yes \\
\hline 17 & M & 79 & Gefitinib & L858R & L858R & Yes \\
\hline 6 & $\mathrm{~F}$ & 50 & Gefitinib & L858R & L858R & Yes \\
\hline 12 & $\mathrm{~F}$ & 58 & Erlotinib & L858R & L858R & Yes \\
\hline 3 & M & 82 & Erlotinib & L858R & L858R & Yes \\
\hline 2 & $\mathrm{~F}$ & 75 & Gefitinib & Exon19 del & ND & Yes \\
\hline 5 & $\mathrm{~F}$ & 61 & Afatinib & L858R & L858R & Yes \\
\hline 28 & $\mathrm{~F}$ & 71 & Gefitinib & L858R & L858R & No \\
\hline 26 & $\mathrm{~F}$ & 63 & Osimertinib & Exon19 del +T790M & ND & No \\
\hline 14 & M & 78 & Gefitinib & G719X & ND & No \\
\hline
\end{tabular}

aMutation detected in the plasma sample collected at any one of the sampling time; ND: Not detected.

sensitizing mutations in EGFR (including L858R, exon 19 deletions, and G719X) and a TKI-resistant mutation (T790M). In addition, the mutation status in the tumor tissue samples from these patients was also analyzed. If a mutation was detected in the plasma and matched that in the tumor tissue of the same patient, the mutation was considered to have been released from the tumor tissue. At the beginning of the TKI treatment, 3 of $11(27 \%)$ plasma samples had detectable mutations before the treatment (Table I).

Detecting EGFR mutations in serial blood samples. Serial blood samples were collected from 8 patients. Samples were collected at the initiation of TKI treatment (or before TKI treatment), at 1, 2, 3, and 5 weeks and then every 3 months. The sensitizing mutations that matched the mutations in the tissue samples were further analyzed in these serial samples (Figure 1). Before TKI treatment, 3 patients (Patients 16, 8, and 6) had detectable EGFR mutations in ctDNA. After TKI treatment, the count of sensitizing mutation reads declined in 1 or 3 weeks. During the follow-up period, 6 patients suffered PD, of which five 
patients (Patients 16, 8, 17, 6, and 3) had an increased number of sensitizing mutations or T790M before PD; however, one patient (Patient 12) had no detectable mutations. The other two patients (Patients 2 and 5) had stable disease and no detectable sensitizing mutations or the T790M mutation during the monitoring periods.

Comparison between the mutation counts and CEA levels. CEA levels in some of the samples were determined and compared with the mutant count in ctDNA. For the six patients who suffered PD, the CEA levels were higher than the cutoff value $(5 \mathrm{ng} / \mathrm{ml})$ in all samples. For the two patients who did not develop PD, the CEA levels were high at the beginning of the treatment and then slowly dropped to below $5 \mathrm{ng} / \mathrm{ml}$. Generally, the changes in CEA levels were not associated with mutational counts in EGFR, except in Patient 6. In Patient 6, both the CEA levels and EGFR mutational counts were high at the beginning, dropped for a period, and then increased again before PD. The comparison of the EGFR mutation counts and CEA levels in blood samples is shown in Figure 2.

\section{Discussion}

In this study, we detected EGFR mutations in the plasma samples of NSCLC patients with the use of targeted NGS and used mutant counts as monitoring markers for TKI treatment. The mutant count varied during the period of TKI treatment. However, there were some patterns in the variation. In some patients (Patients 16,8, and 6), the mutation could be detected at the beginning of the TKI treatment, became undetectable for a few months after undergoing TKI treatment, and then reappeared before PD. Five of six patients who suffered PD (Patients 16, 8, 17, 6, and 3) had detectable mutations before PD; only one (Patient 12) had no detectable mutations before PD. In contrast, two patients (Patients 2 and 5) did not develop PD during the monitoring period and had no detectable EGFR mutations at any sampling time. Therefore, EGFR mutations in the plasma correctly predicted TKI responses in 7 patients. We therefore suggest that the EGFR mutation count in ctDNA can be used to monitor the cancer status during TKI treatment.

CEA has been used as a marker for monitoring the recurrence of various cancers. We investigated the prediction ability of CEA. In most patients, the CEA levels were far above the cutoff value $(5 \mathrm{ng} / \mathrm{ml})$. In two patients (Patients 2 and 5) who did not develop PD, the CEA levels dropped slowly to below $5 \mathrm{ng} / \mathrm{ml}$ after TKI treatment. Therefore, the CEA levels have a predictive ability for PD. However, the changes in CEA levels did not reflect the TKI response very well. In contrast, EGFR mutations dropped after treatment, reflecting the effectiveness of TKI at an early treatment stage. Thus, mutant EGFR DNA can be a better prediction marker.
Traditional NGS has high error rates, making it less sensitive for detecting rare mutant alleles. This is because NGS procedures need to apply error-prone PCR in several steps, and the sequencing step itself also generates errors. It has been shown that the error rate of the MiSeq platform of Illumina is between 0.006 and 0.01 per base (41). Molecular barcoding technology was developed to differentiate true mutations from artifact mutations derived from sequencing. A unique barcode is attached to each DNA fragment during library construction. After PCR amplification and sequencing, the barcode sequence can be retrieved from the sequence. Each unique barcode represents an original template. If most sequences derived from a template have a mutation, it is more likely a true mutation. On the other hand, if a mutation only exists in a small portion of the sequences derived from the same template, it is possibly an artifact mutation. Counting the barcode eliminates PCR and sequencing biases, which greatly increases the sensitivity of detecting mutations with an allele frequency as low as $1 \%$ (40). This method has been proven useful in the detection of somatic mutations $(42,43)$.

The amount of loaded ctDNA is also critical. If the starting material has only 100 genomes, a $1 \%$ mutant frequency, which represents only one read count, is unlikely to be verified as a true positive. Therefore, for diagnostic purposes, detection of low allele frequency mutations requires a sufficient amount of ctDNA and therefore a larger volume of plasma, which can be difficult to obtain in clinical practice. However, for monitoring purposes, a highly sensitive assay is not necessary. When the treatment fails to control the disease, an elevation of the tumor burden will lead to an increase in the ctDNA amount, as well as in the ratio of tumor-derived DNA in the ctDNA. Thus, the mutations would be detected easier. Therefore, no detection of mutations may reveal the effectiveness of TKI treatment, while detection of mutations may indicate treatment failure.

In conclusion, using NGS, we have detected mutations in the plasma that are identical to those in paired lung cancer tissues and found that the mutant genes in the plasma can be a marker to monitor the effectiveness of TKI treatment.

\section{Conflicts of Interest}

The Authors declare no competing financial interests regarding this study.

Figure 2. EGFR mutation counts and CEA levels detected in the blood of NSCLC patients during TKI treatment. The left Y-axis represents the mutation count of either sensitizing mutation (L858R, exon 19 deletion, or $G 719 \mathrm{~A} / L 861 \mathrm{~A})$ that matched the mutation in the tissue samples or the resistant mutation (T790M). The right Y-axis represents the level of CEA. 
A Patient 16

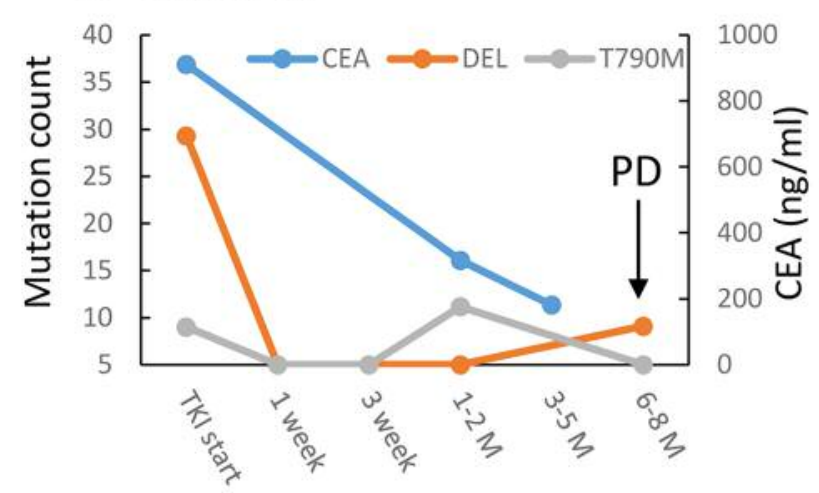

B Patient 8

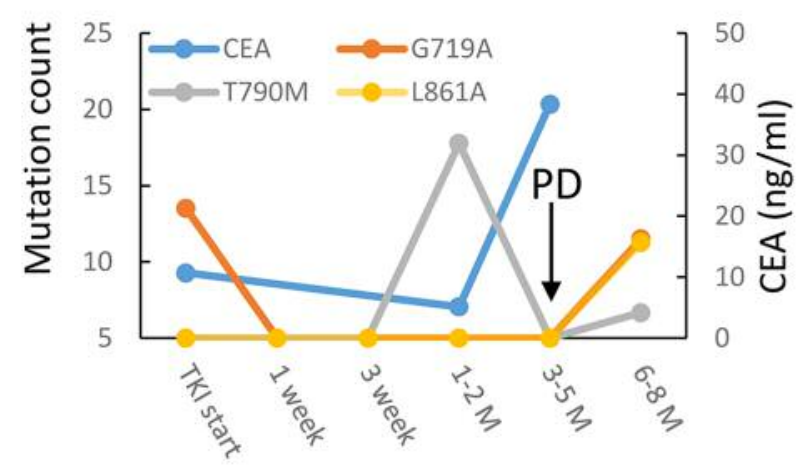

C Patient 17
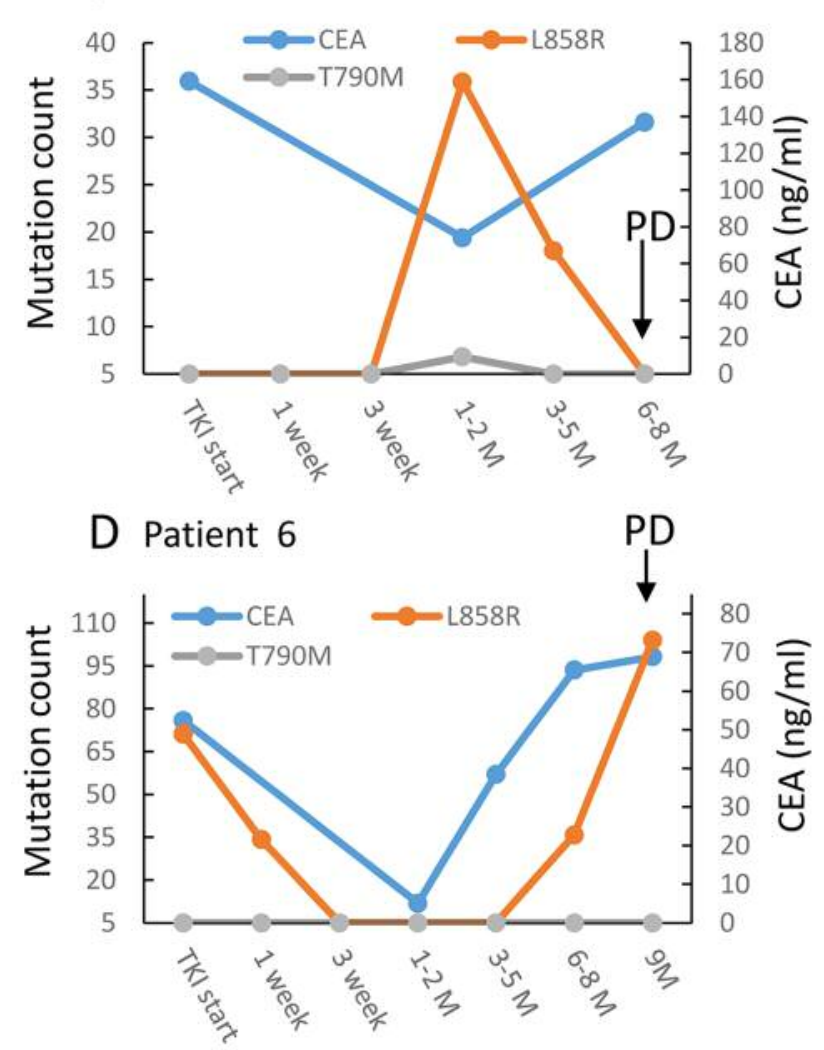

E Patient 12

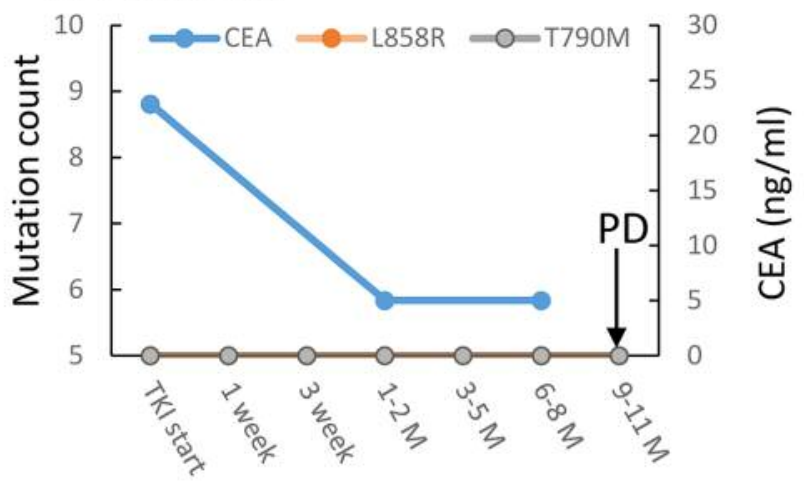

F Patient 3

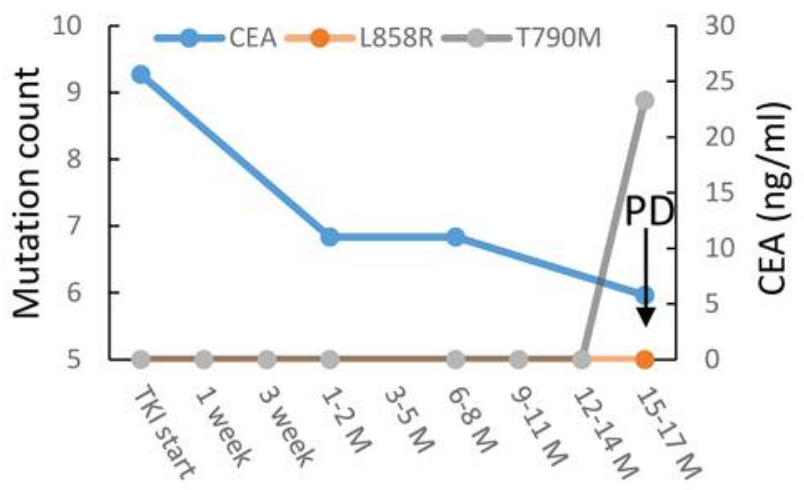

G Patient 2

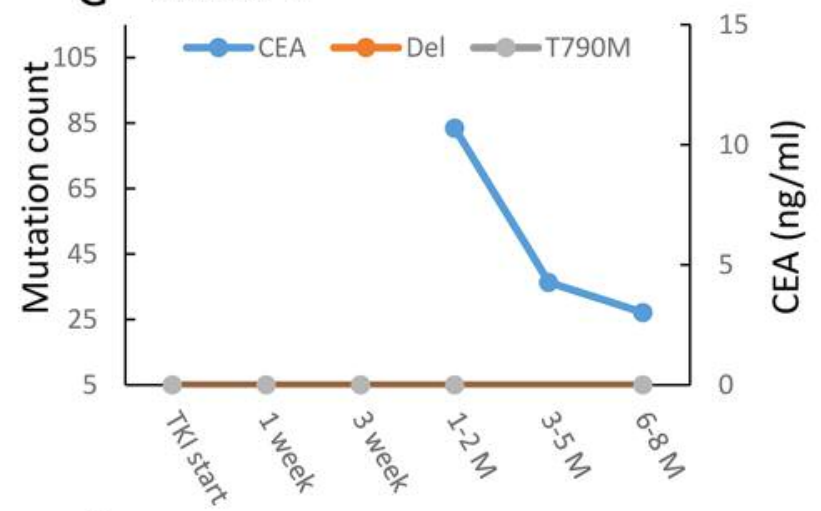

$\mathrm{H}$ Patient 5

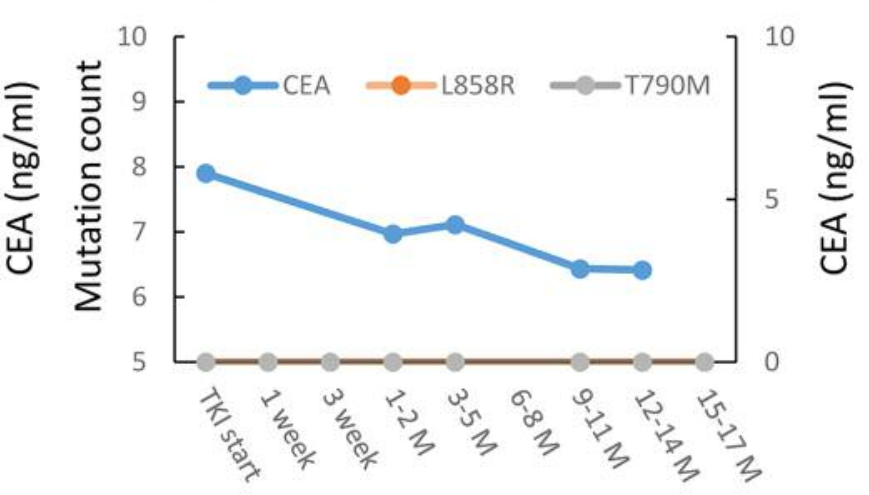




\section{Authors' Contributions}

Conceived and designed the experiments: CT Yang, CL Wang, and CC Chiou. Collected samples: CT Yang, CL Wang, CY Liu, and HW Ko. Conducted the experiments: CL Wang, and JD Luo. Analyzed the data: CC Chiou, JD Luo, and CL Wang. Wrote the paper: CC Chiou, JD Luo, and CT Yang.

\section{Acknowledgements}

The Authors would like to thank Dr. Chia-lung Tsai and Dr. YuanMing Yeh in the Genomic Medicine Research Core Laboratory of Chang Gung Memorial Hospital for the conduction of sequencing and data analysis. This study was supported by a grant form Chang Gung Memorial Hospital (CIRPG3D0291-- CIRPG3D0293).

\section{References}

1 Ang MK and Mok TSK: Twenty-five years of respirology: Advances in lung cancer. Respirology 25(1): 26-31, 2020. PMID: 31840890. DOI: 10.1111/resp.13745

$2 \mathrm{Li} \mathrm{XY,} \mathrm{Lin} \mathrm{JZ} \mathrm{and} \mathrm{Yu} \mathrm{SH:} \mathrm{Front-line} \mathrm{therapy} \mathrm{in} \mathrm{advanced} \mathrm{non-}$ small cell lung cancer with sensitive epidermal growth factor receptor mutations: A network meta-analysis. Clin Ther, 2020. PMID: 31937461. DOI: 10.1016/j.clinthera.2019.12.006

3 Raben D, Helfrich BA, Chan D, Johnson G and Bunn PA, Jr.: Zd1839, a selective epidermal growth factor receptor tyrosine kinase inhibitor, alone and in combination with radiation and chemotherapy as a new therapeutic strategy in non-small cell lung cancer. Semin Oncol 29(1 Suppl 4): 37-46, 2002. PMID: 11894012. DOI: $10.1053 /$ sonc.2002.31521

4 Andrews Wright NM and Goss GD: Third-generation epidermal growth factor receptor tyrosine kinase inhibitors for the treatment of non-small cell lung cancer. Transl Lung Cancer Res 8(Suppl 3): S247-s264, 2019. PMID: 31857949. DOI: 10.21037/tlcr.2019.06.01

5 Nguyen KS, Kobayashi S and Costa DB: Acquired resistance to epidermal growth factor receptor tyrosine kinase inhibitors in non-small-cell lung cancers dependent on the epidermal growth factor receptor pathway. Clin Lung Cancer 10(4): 281-289, 2009. PMID: 19632948. DOI: 10.3816/CLC.2009.n.039

6 Ahmed SM and Salgia R: Epidermal growth factor receptor mutations and susceptibility to targeted therapy in lung cancer. Respirology 11(6): 687-692, 2006. PMID: 17052295. DOI: 10.1111/j.1440-1843.2006.00887.x

7 Wang Q, Yang S, Wang K and Sun SY: Met inhibitors for targeted therapy of egfr tki-resistant lung cancer. J Hematol Oncol 12(1): 63, 2019. PMID: 31227004. DOI: 10.1186/s13045-019-0759-9

8 Porcel JM: Biomarkers in the diagnosis of pleural diseases: A 2018 update. Ther Adv Respir Dis 12: 1753466618808660 , 2018. PMID: 30354850 . DOI: $10.1177 / 1753466618808660$

9 Gao Y, Song P, Li H, Jia H and Zhang B: Elevated serum cea levels are associated with the explosive progression of lung adenocarcinoma harboring egfr mutations. BMC Cancer 17(1): 484, 2017. PMID: 28705152. DOI: 10.1186/s12885-017-3474-3

10 Diaz LA Jr. and Bardelli A: Liquid biopsies: Genotyping circulating tumor DNA. J Clin Oncol 32(6): 579-586, 2014. PMID: 24449238. DOI: $10.1200 /$ jco.2012.45.2011

11 Dakubo GD: Cancer biomarkers in body fluids. Biomarkers in circulation. Springer International Publishing, Cham, Switzerland, 2017. DOI: $10.1007 / 978-3-319-48360-3$
12 Guibert N, Hu Y, Feeney N, Kuang Y, Plagnol V, Jones G, Howarth K, Beeler JF, Paweletz CP and Oxnard GR: Ampliconbased next-generation sequencing of plasma cell-free DNA for detection of driver and resistance mutations in advanced nonsmall cell lung cancer. Ann Oncol 29(4): 1049-1055, 2018. PMID: 29325035. DOI: 10.1093/annonc/mdy005

13 Malapelle U, Mayo de-Las-Casas C, Rocco D, Garzon M, Pisapia P, Jordana-Ariza N, Russo M, Sgariglia R, De Luca C, Pepe F, Martinez-Bueno A, Morales-Espinosa D, Gonzalez-Cao M, Karachaliou N, Viteri Ramirez S, Bellevicine C, Molina-Vila MA, Rosell R and Troncone G: Development of a gene panel for nextgeneration sequencing of clinically relevant mutations in cell-free DNA from cancer patients. Br J Cancer 116(6): 802-810, 2017. PMID: 28170370. DOI: 10.1038/bjc.2017.8

14 Garrigou S, Perkins G, Garlan F, Normand C, Didelot A, Le Corre D, Peyvandi S, Mulot C, Niarra R, Aucouturier P, Chatellier G, Nizard P, Perez-Toralla K, Zonta E, Charpy C, Pujals A, Barau C, Bouche O, Emile JF, Pezet D, Bibeau F, Hutchison JB, Link DR, Zaanan A, Laurent-Puig P, Sobhani I and Taly V: A study of hypermethylated circulating tumor DNA as a universal colorectal cancer biomarker. Clin Chem 62(8): 1129-1139, 2016. PMID: 27251038. DOI: 10.1373/clinchem.2015.253609

15 Johnson PJ and Lo YM: Plasma nucleic acids in the diagnosis and management of malignant disease. Clin Chem 48(8): 11861193, 2002. PMID: 12142371. DOI:10.1093/clinchem/48.8.1186

16 Lee JH and Kim DK: Microsatellite instability of nuclear and mitochondrial dnas in gastric carcinogenesis. Asian Pac J Cancer Prev 15(19): 8029-8032, 2014. PMID: 25338979. DOI: 10.7314/APJCP.2014.15.19.8027

17 Vlassov VV, Laktionov PP and Rykova EY: Circulating nucleic acids as a potential source for cancer biomarkers. Curr Mol Med 10(2): 142-165, 2010. PMID: 20196731. DOI: $10.2174 / 156652410790963295$

18 Costantini A, Takam Kamga P, Dumenil C, Chinet T, Emile JF and Giroux Leprieur E: Plasma biomarkers and immune checkpoint inhibitors in non-small cell lung cancer: New tools for better patient selection? Cancers (Basel) 11(9), 2019. PMID: 31470546. DOI: 10.3390/cancers 11091269

$19 \mathrm{Li} \mathrm{B}, \mathrm{Pu} \mathrm{K}, \mathrm{Ge} \mathrm{L}$ and Wu X: Diagnostic significance assessment of the circulating cell-free DNA in ovarian cancer: An updated meta-analysis. Gene 714: 143993, 2019. PMID: 31330238. DOI: 10.1016/j.gene. 2019.143993

20 van der Pol Y and Mouliere F: Toward the early detection of cancer by decoding the epigenetic and environmental fingerprints of cell-free DNA. Cancer Cell 36(4): 350-368, 2019. PMID: 31614115. DOI: 10.1016/j.ccell.2019.09.003

21 Wang W, Song Z and Zhang Y: A comparison of ddpcr and arms for detecting egfr $\mathrm{t} 790 \mathrm{~m}$ status in ctdna from advanced nsclc patients with acquired egfr-tki resistance. Cancer Med 6(1): 154162, 2017. PMID: 28000387. DOI: 10.1002/cam4.978

22 Spindler KL, Pallisgaard N, Andersen RF, Brandslund I and Jakobsen A: Circulating free DNA as biomarker and source for mutation detection in metastatic colorectal cancer. PLoS One 10(4): e0108247, 2015. PMID: 25875772. DOI: 10.1371/ journal.pone.0108247

23 Yoshida H, Kim YH, Ozasa H, Nagai H, Sakamori Y, Tsuji T, Nomizo T, Funazo T, Yasuda Y and Hirai T: Egfr t790m detection in circulating tumor DNA from non-small cell lung cancer patients using the pna-lna clamp method. Anticancer Res 37(5): 27212725, 2017. PMID: 28476851. DOI: 10.21873/anticanres.11623 
24 Luo JD, Chan EC, Shih CL, Chen TL, Liang Y, Hwang TL and Chiou CC: Detection of rare mutant k-ras DNA in a single-tube reaction using peptide nucleic acid as both pcr clamp and sensor probe. Nucleic Acids Res 34(2): e12, 2006. PMID: 16432256. DOI: $10.1093 /$ nar/gnj008

25 Albitar A, Ma W, DeDios I, Estella J, Ahn I, Farooqui M, Wiestner A and Albitar M: Using high-sensitivity sequencing for the detection of mutations in btk and plcgamma2 genes in cellular and cell-free DNA and correlation with progression in patients treated with btk inhibitors. Oncotarget 8(11): 17936-17944, 2017. PMID: 28212557. DOI: 10.18632/oncotarget.15316

26 Iwama E, Sakai K, Azuma K, Harada T, Harada D, Nosaki K, Hotta K, Ohyanagi F, Kurata T, Fukuhara T, Akamatsu H, Goto K, Shimose T, Kishimoto J, Nakanishi Y, Nishio K and Okamoto I: Monitoring of somatic mutations in circulating cell-free DNA by digital pcr and next-generation sequencing during afatinib treatment in patients with lung adenocarcinoma positive for egfr activating mutations. Ann Oncol 28(1): 136-141, 2017. PMID: 28177428. DOI: 10.1093/annonc/mdw531

27 Jovelet C, Madic J, Remon J, Honore A, Girard R, Rouleau E, Andre B, Besse B, Droniou M and Lacroix L: Crystal digital droplet pcr for detection and quantification of circulating egfr sensitizing and resistance mutations in advanced non-small cell lung cancer. PLoS One 12(8): e0183319, 2017. PMID: 28829811. DOI: 10.1371/journal.pone.0183319

28 Yang K, Li J, Zhao J, Ren P, Wang Z, Wei B, Dong B, Sun R, Wang X, Groen HJM, Ma J and Guo Y: Developing ultrasensitive library-aliquot-based droplet digital pcr for detecting $7790 \mathrm{~m}$ in plasma-circulating tumor DNA of non-smallcell-lung-cancer patients. Anal Chem 90(19): 11203-11209, 2018. PMID: 30156405. DOI: 10.1021/acs.analchem.8b01776

29 Oxnard GR, Paweletz CP, Kuang Y, Mach SL, O’Connell A, Messineo MM, Luke JJ, Butaney M, Kirschmeier P, Jackman DM and Janne PA: Noninvasive detection of response and resistance in egfr-mutant lung cancer using quantitative nextgeneration genotyping of cell-free plasma DNA. Clin Cancer Res 20(6): 1698-1705, 2014. PMID: 24429876. DOI: 10.1158/1078-0432.Ccr-13-2482

30 Page K, Guttery DS, Fernandez-Garcia D, Hills A, Hastings RK, Luo J, Goddard K, Shahin V, Woodley-Barker L, Rosales BM, Coombes RC, Stebbing J and Shaw JA: Next generation sequencing of circulating cell-free DNA for evaluating mutations and gene amplification in metastatic breast cancer. Clin Chem 63(2): 532-541, 2017. PMID: 27940449. DOI: 10.1373/clinchem.2016.261834

31 Thompson JC, Yee SS, Troxel AB, Savitch SL, Fan R, Balli D, Lieberman DB, Morrissette JD, Evans TL, Bauml J, Aggarwal C, Kosteva JA, Alley E, Ciunci C, Cohen RB, Bagley S, Stonehouse-Lee S, Sherry VE, Gilbert E, Langer C, Vachani A and Carpenter EL: Detection of therapeutically targetable driver and resistance mutations in lung cancer patients by nextgeneration sequencing of cell-free circulating tumor DNA. Clin Cancer Res 22(23): 5772-5782, 2016. PMID: 27601595. DOI: 10.1158/1078-0432.CCR-16-1231

32 Desai AN and Jere A: Next-generation sequencing: Ready for the clinics? Clin Genet 81(6): 503-510, 2012. PMID: 22375550. DOI: $10.1111 / \mathrm{j} .1399-0004.2012 .01865 . x$

33 Gullapalli RR, Lyons-Weiler M, Petrosko P, Dhir R, Becich MJ and LaFramboise WA: Clinical integration of next-generation sequencing technology. Clin Lab Med 32(4): 585-599, 2012. PMID: 23078661. DOI: 10.1016/j.cll.2012.07.005
34 Kerr KM and Lopez-Rios F: Precision medicine in nsclc and pathology: How does alk fit in the pathway? Ann Oncol 27(Suppl 3): iii16-iii24, 2016. PMID: 27573752. DOI: 10.1093/annonc/mdw302

35 Dagogo-Jack I, Brannon AR, Ferris LA, Campbell CD, Lin JJ, Schultz KR, Ackil J, Stevens S, Dardaei L, Yoda S, Hubbeling H, Digumarthy SR, Riester M, Hata AN, Sequist LV, Lennes IT, Iafrate AJ, Heist RS, Azzoli CG, Farago AF, Engelman JA, Lennerz JK, Benes CH, Leary RJ, Shaw AT and Gainor JF: Tracking the evolution of resistance to alk tyrosine kinase inhibitors through longitudinal analysis of circulating tumor DNA. JCO Precis Oncol 2018, 2018. PMID: 29376144. DOI: 10.1200/po.17.00160

36 Frenel JS, Carreira S, Goodall J, Roda D, Perez-Lopez R, Tunariu N, Riisnaes R, Miranda S, Figueiredo I, Nava-Rodrigues D, Smith A, Leux C, Garcia-Murillas I, Ferraldeschi R, Lorente D, Mateo J, Ong M, Yap TA, Banerji U, Gasi Tandefelt D, Turner N, Attard G and de Bono JS: Serial next-generation sequencing of circulating cell-free DNA evaluating tumor clone response to molecularly targeted drug administration. Clin Cancer Res 21(20): 4586-4596, 2015. PMID: 26085511. DOI: 10.1158/1078-0432.Ccr-15-0584

37 Quail MA, Kozarewa I, Smith F, Scally A, Stephens PJ, Durbin R, Swerdlow H and Turner DJ: A large genome center's improvements to the illumina sequencing system. Nat Methods 5(12): 1005-1010, 2008. PMID: 19034268. DOI: $10.1038 /$ nmeth. 1270

38 Kinde I, Wu J, Papadopoulos N, Kinzler KW and Vogelstein B: Detection and quantification of rare mutations with massively parallel sequencing. Proc Natl Acad Sci USA 108(23): 95309535, 2011. PMID: 21586637. DOI: 10.1073/pnas.1105422108

39 Eisenhauer EA, Therasse P, Bogaerts J, Schwartz LH, Sargent D, Ford R, Dancey J, Arbuck S, Gwyther S, Mooney M, Rubinstein L, Shankar L, Dodd L, Kaplan R, Lacombe D and Verweij J: New response evaluation criteria in solid tumours: Revised recist guideline (version 1.1). Eur J Cancer 45(2): 228-247, 2009. PMID: 19097774. DOI: 10.1016/j.ejca.2008. 10.026

$40 \mathrm{Xu} \mathrm{C}$, Nezami Ranjbar MR, Wu Z, DiCarlo J and Wang Y: Detecting very low allele fraction variants using targeted DNA sequencing and a novel molecular barcode-aware variant caller. BMC Genomics 18(1): 5, 2017. PMID: 28049435. DOI: 10.1186/s12864-016-3425-4

41 Schirmer M, Ijaz UZ, D'Amore R, Hall N, Sloan WT and Quince C: Insight into biases and sequencing errors for amplicon sequencing with the illumina miseq platform. Nucleic Acids Res 43(6): e37, 2015. PMID: 25586220. DOI: 10.1093/nar/gku1341

42 Peng Q, Vijaya Satya R, Lewis M, Randad P and Wang Y: Reducing amplification artifacts in high multiplex amplicon sequencing by using molecular barcodes. BMC Genomics 16: 589, 2015. PMID: 26248467. DOI: 10.1186/s12864-015-1806-8

43 Kennedy SR, Schmitt MW, Fox EJ, Kohrn BF, Salk JJ, Ahn EH, Prindle MJ, Kuong KJ, Shen JC, Risques RA and Loeb LA: Detecting ultralow-frequency mutations by duplex sequencing. Nat Protoc 9(11): 2586-2606, 2014. PMID: 25299156. DOI: 10.1038/nprot.2014.170

Received February 25, 2020

Revised March 13, 2020

Accepted March 14, 2020 